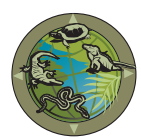

\title{
Unusual Thermoregulatory Behavior by a Northern House Gecko, Hemidactylus flaviviridis Rüppell 1835
}

Debaprasad Sengupta and Parag Nigam

Wildlife Institute of India, Dehradun - 248001, Uttarakhand, India

(debaprasad.sengupta40@hotmail.com,nigamp@wii.gov.in)

$\mathrm{T}$ he Northern House Gecko (Hemidactylus flaviviridis; Fig. 1 ) is a nocturnally active human commensal (Das 2002; Daniel 2002). For 15-20 min beginning at $1242 \mathrm{~h}$ on 18 May 2017 at the Sariska Campus, Sadar Beat, Sariska Tiger Reserve, Rajasthan, India $\left(27^{\circ} 23^{\prime} 16.8^{\prime \prime} \mathrm{N}, 76^{\circ} 22^{\prime} 33.6^{\prime \prime E}\right.$; Fig. 2 ), we observed a juvenile Northern House Gecko shuttling at 45-50-sec intervals in and out of the water in an artificial pool constructed as a watering hole for animals in the semiarid landscape. Ambient temperature was $44.3^{\circ} \mathrm{C}$ and the water temperature was $40.5^{\circ} \mathrm{C}$. The body temperature of the lizard was $40.8^{\circ} \mathrm{C}$ while the head and body were in the water and $2.2^{\circ} \mathrm{C}$ warmer when dry. We saw no evidence of drinking while the gecko was in the water.

The fact that nocturnal geckos such as $H$. flaviviridis would rarely encounter such an extremely high ambient

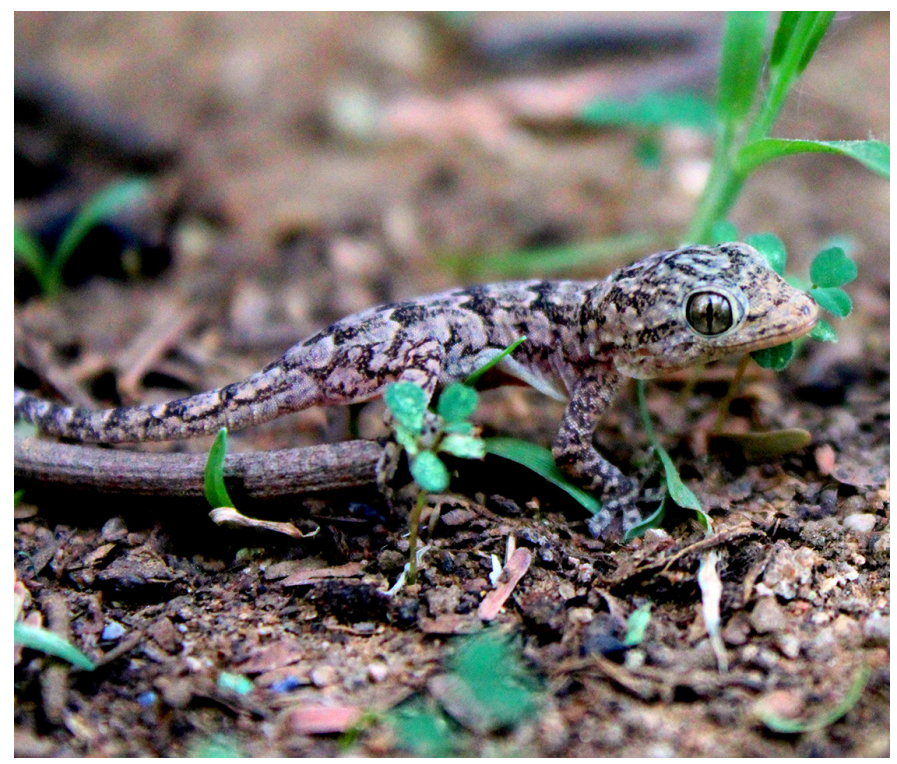

Fig. 1. The juvenile Northern House Gecko (Hemidactylus flaviviridis) that had been shuttling in and out of the water of an artificial pool in the Sariska Tiger Reserve, Rajasthan, India. Photograph by Debaprasad Sengupta. temperature and the lower body temperature of the lizard in the water suggest that this behavior was thermoregulatory in nature. Veeranagoudar et al. (2010) documented similar behavior by a gravid South Indian Rock Agama (Psammophilus dorsalis). To the best of our knowledge, this is the first report of a gecko using an artificial pool to thermoregulate.

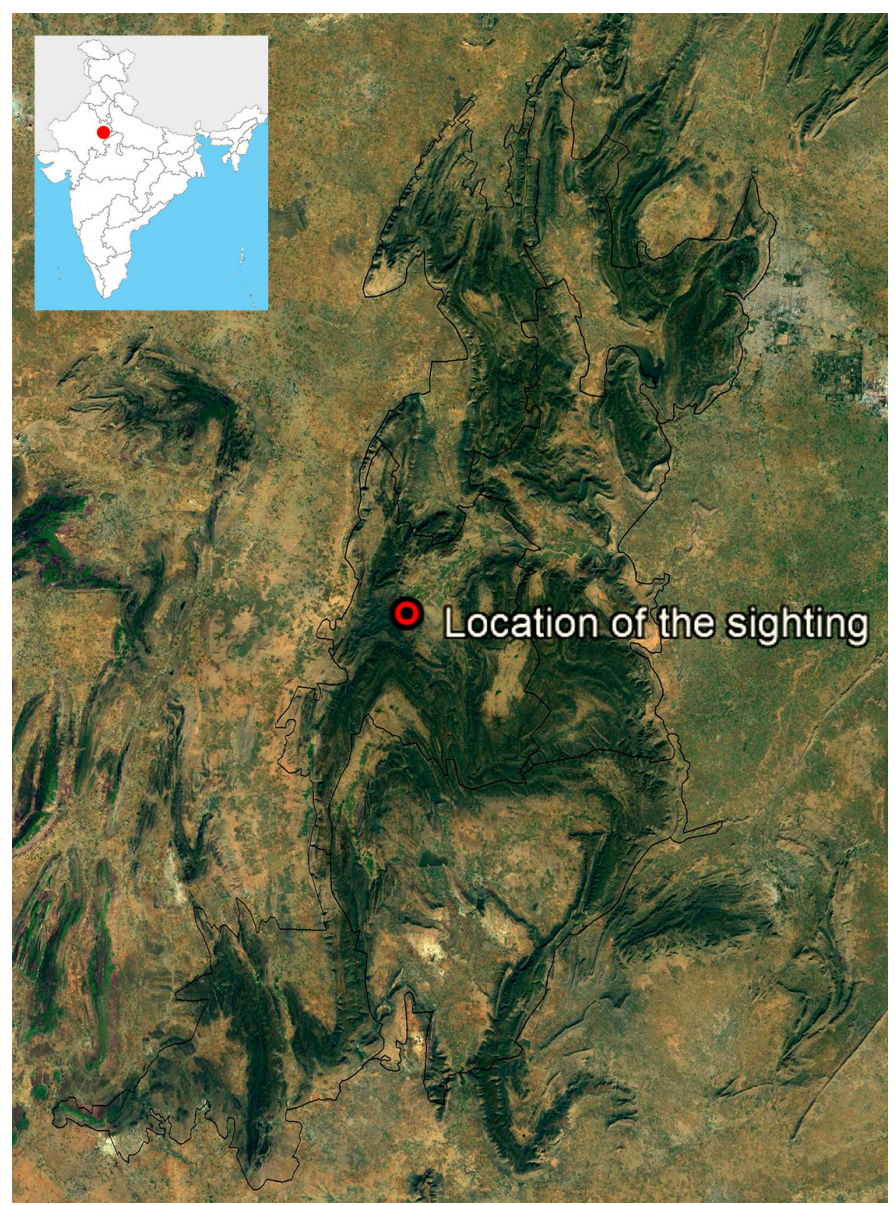

Fig. 2. Google Earth ${ }^{\odot}$ image of the Sariska Tiger Reserve in Rajasthan, India and the locality of the observation described herein. 


\section{Acknowledgements}

This work was conducted under the auspices of the Sariska Tiger Project funded by the National Tiger Conservation Authority (NTCA) in collaboration with the Wildlife Institute of India and the Rajasthan Forest Department. Forest officials of the Sariska Tiger Reserve granted permission to work in the reserve. Ratanlal Gurjar and Rajesh Meena assisted us in the field.

\section{Literature Cited}

Daniel, J.C. 2002. The Book of Indian Reptiles and Amphibians. The Bombay Natural History Society \& Oxford University Press, Mumbai, India.

Das, I. 2002. Snakes and other Reptiles of India. New Holland, London, UK.

Veeranagoudar, D.K., B.A. Shanbhag, and S.K. Saidapur. 2010. A novel thermoregulatory behavior in a gravid rock lizard, Psammophilus dorsalis. Herpetology Notes 3: 101-103. 